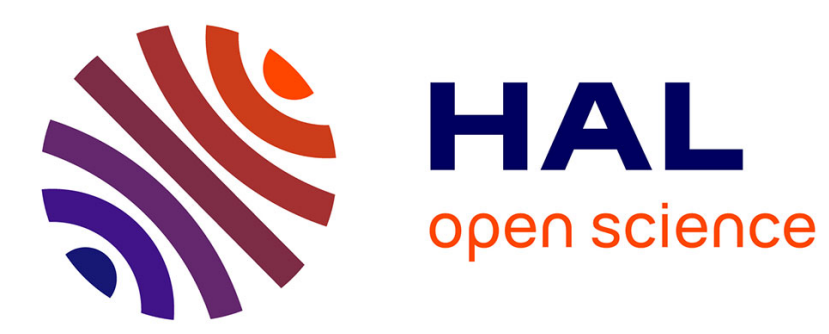

\title{
Elastic properties, thermal stability, and thermodynamic parameters of MoAlB
}

Sankalp Kota, Matthias Agne, Eugenio W Zapata-Solvas, Olivier Dezellus, Diego Lopez, Bruno Gardiola, Miladin Radovic, Michel W Barsoum

\section{- To cite this version:}

Sankalp Kota, Matthias Agne, Eugenio W Zapata-Solvas, Olivier Dezellus, Diego Lopez, et al.. Elastic properties, thermal stability, and thermodynamic parameters of MoAlB. Physical Review B: Condensed Matter and Materials Physics (1998-2015), 2017, 95, pp.144108. 10.1103/PhysRevB.95.144108 . hal-01508204

\section{HAL Id: hal-01508204 https://hal.science/hal-01508204}

Submitted on 14 Apr 2017

HAL is a multi-disciplinary open access archive for the deposit and dissemination of scientific research documents, whether they are published or not. The documents may come from teaching and research institutions in France or abroad, or from public or private research centers.
L'archive ouverte pluridisciplinaire HAL, est destinée au dépôt et à la diffusion de documents scientifiques de niveau recherche, publiés ou non, émanant des établissements d'enseignement et de recherche français ou étrangers, des laboratoires publics ou privés. 


\title{
Elastic properties, thermal stability, and thermodynamic parameters of MoAIB
}

\author{
Sankalp Kota, ${ }^{1}$ Matthias Agne, ${ }^{2}$ Eugenio Zapata-Solvas, ${ }^{3}$ Olivier Dezellus, ${ }^{4}$ Diego Lopez, ${ }^{5}$ Bruno Gardiola, ${ }^{4}$ \\ Miladin Radovic, ${ }^{5}$ and Michel W. Barsoum ${ }^{1, *}$ \\ ${ }^{1}$ Department of Materials Science and Engineering, Drexel University, Philadelphia, Pennsylvania 19104, USA \\ ${ }^{2}$ Department of Materials Science and Engineering, Northwestern University, Evanston, Illinois 60208, USA \\ ${ }^{3}$ Centre for Nuclear Engineering \& Department of Materials, Imperial College London, London SW7 2AZ, United Kingdom \\ ${ }^{4}$ Laboratoire des Multimatériaux et Interfaces, Université Claude Bernard LYON1, UMR CNRS 5615, F-69622 Villeurbanne, France \\ ${ }^{5}$ Department of Mechanical Engineering, Texas A\&M University, College Station, Texas 77843, USA
}

(Received 27 January 2017; published 13 April 2017)

\begin{abstract}
MoAlB is the first and, so far, the only transition-metal boride that forms alumina when heated in air and is thus potentially useful for high-temperature applications. Herein, the thermal stability in argon and vacuum atmospheres and the thermodynamic parameters of bulk polycrystalline MoAlB were investigated experimentally. At temperatures above $1708 \mathrm{~K}$, in vacuum and inert atmospheres, this compound incongruently melts into the binary MoB and liquid aluminum metal as confirmed by differential thermal analysis, quenching experiments, $\mathrm{x}$-ray diffraction, and scanning electron microscopy. Making use of that information together with heat-capacity measurements in the 4-1000-K temperature range-successfully modeled as the sum of lattice, electronic, and dilation contributions - the standard enthalpy, entropy, and free energy of formation are computed and reported for the full temperature range. The standard enthalpy of formation of MoAlB at $298 \mathrm{~K}$ was found to be $-132 \pm 3.2 \mathrm{~kJ} / \mathrm{mol}$. Lastly, the thermal conductivity values are computed and modeled using a variation of the Slack model in the 300-1600-K temperature range.
\end{abstract}

DOI: 10.1103/PhysRevB.95.144108

\section{INTRODUCTION}

Transition-metal borides (TMBs) are prized refractory materials for their high melting points, high hardness, and excellent electrical and thermal conductivities. These properties, among others, make them useful for applications ranging from wear-resistant coatings [1], refractory crucibles, high-temperature (HT) electrodes [2], solar absorbers [3], permanent magnets [4], and primary battery electrodes [5-7]. Despite renewed interest in the binary TMBs for structural aerospace components related to hypersonic flight and atmospheric reentry of space vehicles, these compounds in their nominally pure form suffer from poor oxidation resistance in air above $1200^{\circ} \mathrm{C}[8,9]$.

Recently, we reported on the bulk synthesis of a layered ternary transition-metal boride-MoAlB - that forms a protective and adherent alumina $\mathrm{Al}_{2} \mathrm{O}_{3}$ scale when heated in air at temperatures up to $1400^{\circ} \mathrm{C}$ [10]. In that regard, MoAlB overcomes many limitations of binary TMBs and is quite similar to the layered aluminum- (Al-) containing $M_{n+1} A X_{n}$ (MAX) phases $\mathrm{Ti}_{2} \mathrm{AlC}, \mathrm{Ti}_{3} \mathrm{AlC}_{2}$, and $\mathrm{Cr}_{2} \mathrm{AlC}$, which form highly protective aluminum oxide scales during high-temperature oxidation in air [11-13]. More recently, Chaix-Pluchery et al. reported density-functional-theory(DFT-) calculated phonon density of states (pDOS) of MoAlB and found excellent matches with the peak positions of the experimentally measured Raman spectra [14].

MoAlB has a layered orthorhombic structure consisting of a molybdenum boride (MoB) sublattice, similar to that of the orthorhombic polymorph of MoB, interleaved by two Al layers [15]. Previous work on this compound focused on the growth of MoAlB single crystals and the partial

*Corresponding author: barsoumw@drexel.edu substitution of the Mo site with $\mathrm{Cr}$ and W [16-20]. The MoAlB single crystals were shown to have a relatively low hardness (10-13 GPa) compared to most TMBs $[19,20]$ and high room-temperature electrical conductivity $[16,19]$. In addition to its excellent oxidation resistance, our recent work on bulk MoAlB has shown that it has high electrical and thermal conductivities, room-temperature compressive strengths that are close to $2 \mathrm{GPa}$, and a thermal expansion coefficient of $-9.6 \times 10^{-6} \mathrm{~K}^{-1}$ - that is comparable to many other engineering materials (e.g., alumina, yttria-stabilized zirconia, and Ni superalloys) [13,21]. In combination, these properties bode well for the use of MoAlB in HT applications.

However, before such applications can be contemplated, it is vital to know its melting or thermal decomposition temperature. Phase diagrams of the MoAlB system only exist at $1273 \mathrm{~K}$ and indicate MoAlB is in an equilibrium phase at that temperature $T$ [22]. We also noted briefly in our previous work that no melting or reaction peaks were observed when MoAlB samples were studied by differential thermal analysis (DTA) up to $1673 \mathrm{~K}$ in an Ar atmosphere [10].

Knowing the constant-pressure heat-capacity $c_{\mathrm{p}}$ of a solid over a wide $T$ range is also indispensable for calculating its thermodynamic parameters, understanding its electronic structure, the $T$ dependence of thermal conductivity, and equilibrium phase relations. At low $T$ 's, measuring $c_{\mathrm{p}}$ is a well-established technique to estimate the electronic density of states $(\mathrm{eDOS})$ at the Fermi level $N\left(E_{\mathrm{f}}\right)$. For metalliclike conductors, the low- $T c_{\mathrm{p}}$ is given by

$$
c_{\mathrm{p}}=\gamma T+\beta T^{3},
$$

where $\gamma$ and $\beta$ are the coefficients of electronic and lattice heat capacities, respectively. Following the free-electron model, $\gamma$ can be related to $N\left(E_{\mathrm{f}}\right)$ by

$$
N\left(E_{\mathrm{f}}\right)=\frac{3 \gamma}{\pi^{2} k_{\mathrm{B}}^{2}},
$$


where $k_{\mathrm{B}}$ is the Boltzmann constant. Previously, Eq. (1) was used to successfully calculate $\gamma$ and $\beta$ of transition-metal borides [23,24] and the MAX phases [25,26].

The purpose of this paper is to thoroughly characterize the thermal and elastic properties of MoAlB. This is accomplished by determining its thermal stability regime in inert and vacuum atmospheres using DTA, x-ray diffraction (XRD), and quenching experiments to determine the phases present above the decomposition temperature. We also measured $c_{\mathrm{p}}$ over the 4-1000-K temperature range using a relaxation method at low temperatures and differential scanning calorimetry (DSC) at high temperatures. A suitable model was found to capture the temperature dependence of $c_{\mathrm{p}}$. From these results, we estimate the standard enthalpy of the formation of MoAlB and its free-energy functions as well as reevaluated our previously reported temperature dependence of thermal conductivity [10]. We also use resonant ultrasound spectroscopy (RUS) to measure Young's and shear moduli in the 300-1473-K temperature range.

\section{EXPERIMENTAL PROCEDURES}

\section{A. Sample preparation}

Dense predominantly single-phase MoAlB samples were prepared according to a previous report [10]. Briefly, MoB and $\mathrm{Al}$ powders were ball milled in a polyethylene container with zirconia milling balls for $24 \mathrm{~h}$. The mixed powders were precompacted under a load corresponding to $30 \mathrm{MPa}$ and then hot pressed in a boron nitride-coated graphite die under vacuum $(<13.3 \mathrm{~Pa})$ at $1200^{\circ} \mathrm{C}$ for $5 \mathrm{~h}$ under a load corresponding to a stress of $25 \mathrm{MPa}$. The samples were ground and polished progressively down to 800 grit $\mathrm{SiC}$ paper and cut with a diamond wheel to dimensions needed for further characterization.

\section{B. Characterization}

At low temperatures, the $c_{\mathrm{p}}$ of a 16.5-mg rectangular sample $\sim 0$.6-mm thick was measured by the relaxation method using a Quantum Design physical properties measurement system over the 4-303 $\mathrm{K}$ temperature range at a heating rate of $0.2 \mathrm{~K} / \mathrm{min}$. The measurement was conducted under vacuum $\left(10^{-3} \mathrm{~Pa}\right)$. At high $T$ 's, three measurements were acquired using a DSC (NETZCH, Germany) in the 300-1000-K temperature range with a heating rate of $20 \mathrm{~K} / \mathrm{min}$. The DSC was calibrated with a sapphire standard under the same conditions. Two measurements were conducted in a dynamic $\mathrm{N}_{2}$ atmosphere under a flow of $20 \mathrm{ml} / \mathrm{min}$; the third was conducted in a flowing $\mathrm{Ar}$ atmosphere. The samples were placed in either Pt- or $\mathrm{Al}_{2} \mathrm{O}_{3}$-lined Pt crucibles. The $c_{\mathrm{p}}$ was converted from $\mathrm{J} / \mathrm{g} / \mathrm{K}$ to $\mathrm{J} / \mathrm{mol} / \mathrm{K}$ using the molar mass of $133.73 \mathrm{~g} / \mathrm{mol}$. No correction to $c_{\mathrm{p}}$ was made for the small volume fraction of impurity phases known to be present $\left[6 \pm 3\right.$-vol $\% \mathrm{Al}_{3} \mathrm{Mo}$ and $<3$-vol $\% \mathrm{Al}_{2} \mathrm{O}_{3}$, see Fig. 1(a)]. DTA and thermogravimetric analysis (TGA) (Netzsch STA 449F1, Selb, Upper Franconia, Germany) were performed simultaneously under high-purity Ar flow (99.998\%-pure) on samples placed in $\mathrm{Al}_{2} \mathrm{O}_{3}$ crucibles in the $298-1873 \mathrm{~K}$ temperature range, heated at a rate of $10 \mathrm{~K} / \mathrm{min}$.
Quenching experiments were conducted under a primary vacuum (0.1-1.0 Pa) or static Ar environment (99.999\% -pure, $80 \mathrm{kPa})$ in an induction heated vertical tube furnace equipped with a bichromatic pyrometer for temperature measurement. The MoAlB sample was placed inside a graphite crucible suspended by $\mathrm{SiC}$ fibers and an electromagnetic system. After a dwell time at the heat treatment temperature of $1773 \mathrm{~K}$, the electromagnet was switched off, leading to the fall of the graphite crucible and sample directly into cold oil $(273 \mathrm{~K})$ without any exposure to air. The sample was then removed from the oil, cleaned with acetone, and dried before further characterizations.

The elastic constants were measured in the 300-1473 K temperature range using a custom-made high-temperature setup for RUS with a RUSPEC control unit (Magnaflux, Glenview, IL). Disks, $18 \mathrm{~mm}$ in diameter, 2.5-mm high, were subjected to continuous Ar flow during the testing to prevent their oxidation. The high-temperature setup uses three 6-in. single-crystal alumina rods glued to piezoelectric transducers: one of them to transmit ultrasonic waves in the 20 to $500 \mathrm{kHz}$ frequency range at a constant amplitude to the sample. The other two are used to monitor the signal from the sample. RUSPEC software (Magnaflux, Glenview, IL) was used to determine the elastic constants at each temperature from the collected resonant spectra using a procedure described in more detail elsewhere $[27,28]$. Since all samples examined in this paper had polycrystalline structures with random orientations, they were treated as isotropic elastic solids. Thus, two elastic constants, namely, Young's $(E)$ and shear $(G)$ moduli were determined directly from the resonant spectra, whereas the bulk modulus $(B)$ was computed from the triadic relation [29,30]: $B=(E G)(9 G-3 E)^{-1}$.

XRD was conducted on a powder diffractometer (Rigaku SmartLab, Tokyo, Japan) using $\mathrm{Cu} K \alpha_{1}$ radiation $(\lambda=$ $1.540598 \mathrm{~nm})$. Scanning parameters were a $0.04^{\circ}$ step size 100 -s dwelling time per step. The XRD patterns were obtained on the pristine sample's cross section, the sample surfaces after TGA/DTA, and the bulk of the samples after grinding their surfaces with 400 grit $\mathrm{SiC}$ paper. Each XRD pattern is normalized with respect to the most intense peak in that pattern. A scanning electron microscope (SEM) (Zeiss Supra 50VP) and energy dispersive x-ray spectroscope (EDS) (Oxford Instruments) were used to image the samples and analyze the impurities present and their relative elemental compositions.

\section{RESULTS AND DISCUSSION}

\section{A. Sample characterization}

Image analysis of backscattered electron images revealed the presence of $\sim 6 \pm 3$ - vol \% $\mathrm{Al}_{3+x} \mathrm{Mo}_{1-x}$ or $\mathrm{Al}_{8} \mathrm{Mo}_{3}$ and $<3$ vol $\% \mathrm{Al}_{2} \mathrm{O}_{3}$ [see Fig. 1(a)]. XRD results showed the sample to be predominantly single-phase MoAlB as shown on the bottom curve of Fig. 1(b). The density of $6.45 \mathrm{~g} / \mathrm{cm}^{3}$ determined by the Archimedes method suggests that all samples were fully dense.

\section{B. Thermal stability}

A typical DTA/TGA thermogram performed in an $\mathrm{Ar}$ atmosphere is shown in Fig. 1(c). At temperatures below 
(a)

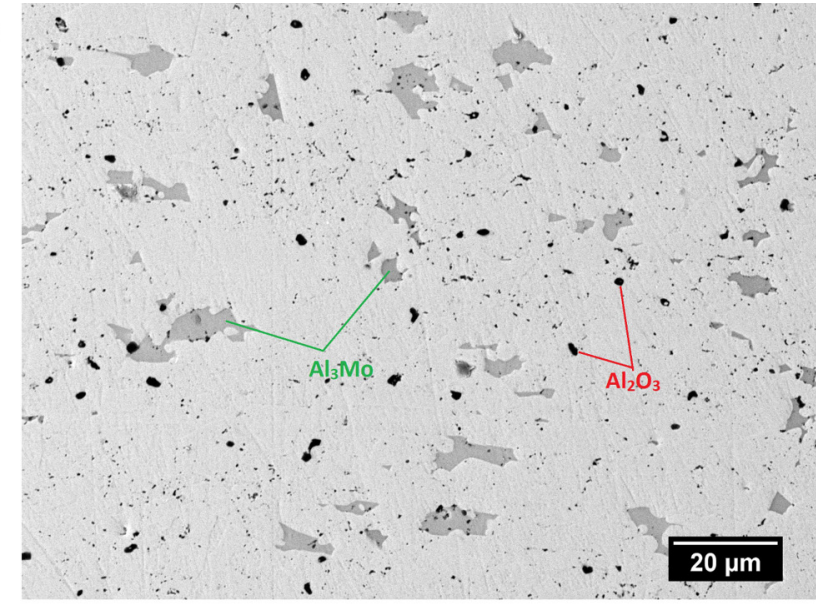

(c)

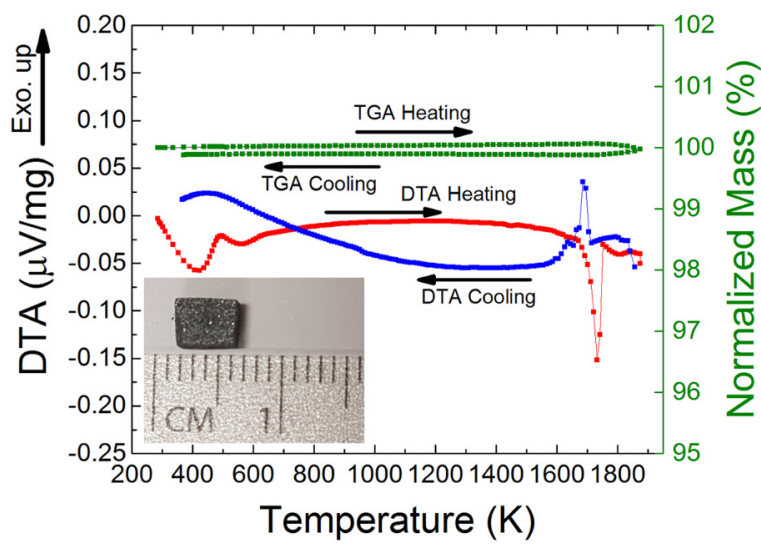

(b)

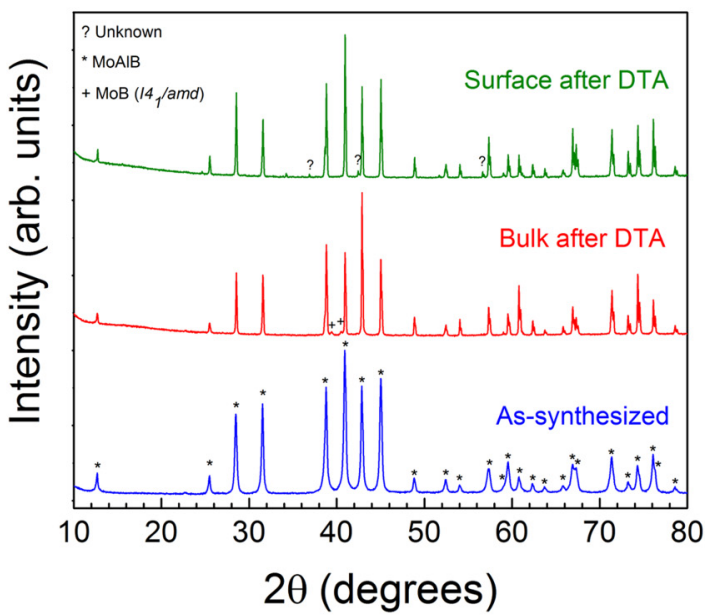

(d)

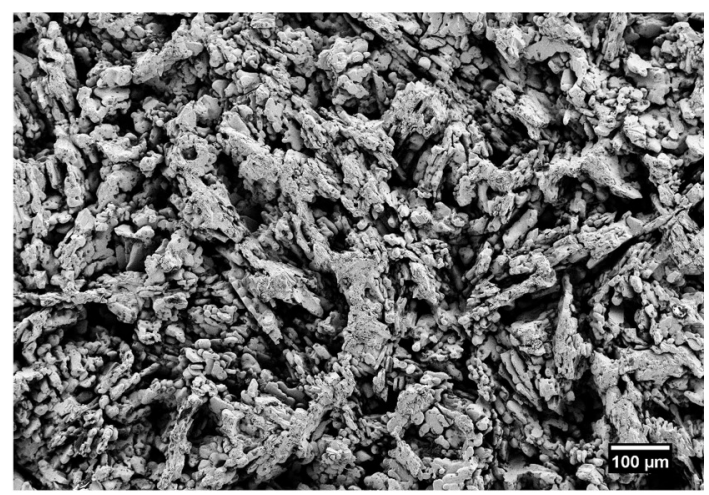

(e)

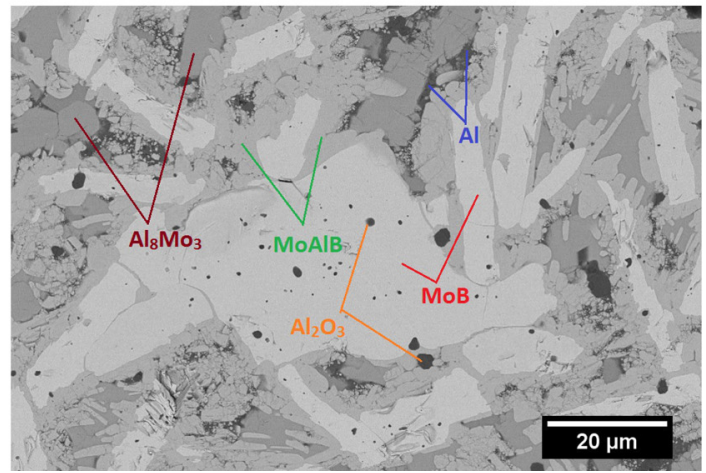

FIG. 1. (a) A backscattered electron micrograph of an as-synthesized and polished MoAlB cross section. (b) XRD on a pristine polished surface (bottom), the sample bulk (middle) after DTA, and surface (top) after DTA. (c) A DTA/TGA thermogram performed under Ar on a dense MoAlB sample. The inset shows a sample after DTA/TGA in Ar. (d) SEM micrograph of bulk cross-sectional morphology after DTA/TGA to $1600^{\circ} \mathrm{C}$ under Ar. (e) A micrograph of the sample surface after annealing at and quenching from $1773 \mathrm{~K}$ under Ar.

$473 \mathrm{~K}$, a small endotherm is present which may be due to the evaporation of adsorbed water from surface pores. Upon further heating above $473 \mathrm{~K}$, relatively little heat flux is observed until a large endothermic peak emerges at $1708 \mathrm{~K}$ with a peak temperature of $1743 \mathrm{~K}$. During cooling, a narrower exothermic peak emerges at $1710 \mathrm{~K}$ with a peak temperature of $1704 \mathrm{~K}$.

After DTA/TGA in Ar, the cross-sectional area of the sample increased by $\sim 50 \%$, and the initially sharp edges of the sample became rounded. In addition, an extremely porous microstructure [Fig. 1(d)] was observed under SEM. EDS on the cross section after DTA/TGA showed an Al:Mo ratio of (0.85-0.93), which is comparable to that of the pristine sample (0.81-0.85). XRD on the sample bulk [middle curve in Fig. 1(b)] showed narrower peaks and some changes in peak intensity ratios, and the emergence of several low intensity peaks at $39.4^{\circ}$ and $40.4^{\circ} 2 \theta$ that correspond to tetragonal MoB (space-group I4/ /amd, ICSD No. 24280). XRD of the sample's surface was also consistent with a sample composed of mostly MoAlB with narrowed peaks. A few new peaksespecially those at $36.9^{\circ}$ and $42.5^{\circ} 2 \theta$-could not be assigned to any known phases, despite our best attempt to match them 


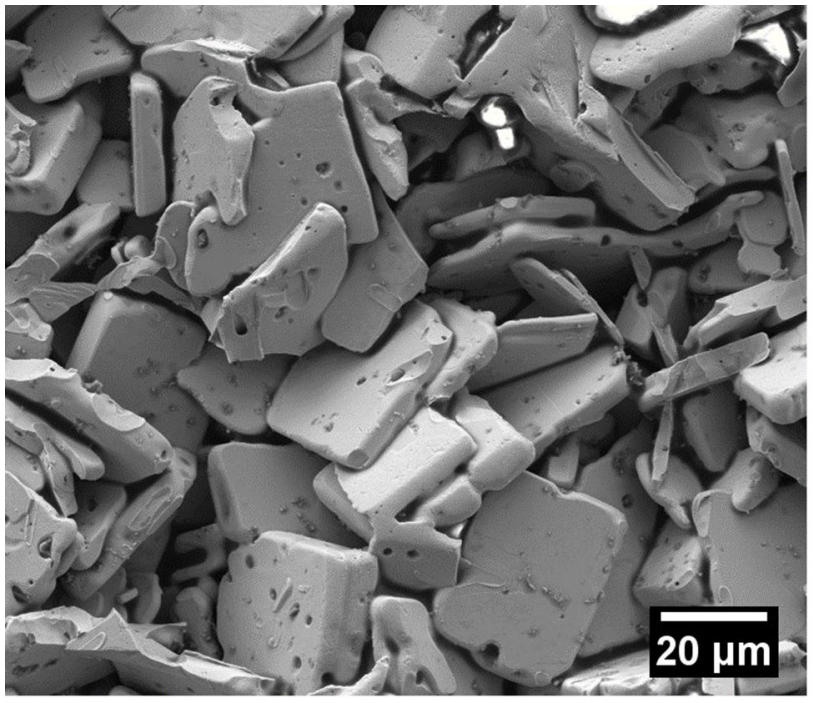

(a)

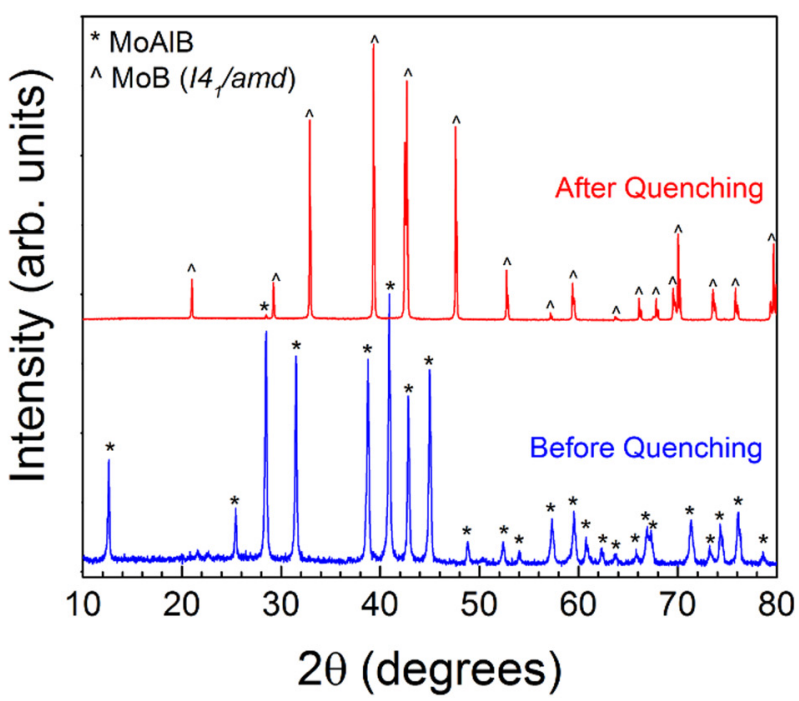

(b)

FIG. 2. (a) Micrograph of sample surface after heating at $1773 \mathrm{~K}$ for $1 \mathrm{~h}$ under vacuum and quenching into cold oil. (b) XRD of the sample surface after annealing under vacuum at $1773 \mathrm{~K}$ and quenching.

to phases in the Mo-Al-B-O system. To elucidate the origin of the peaks in DTA, a MoAlB sample was heated at $1773 \mathrm{~K}$ for $0.5 \mathrm{~h}$ under Ar and quenched into cold oil. A $3.2 \%$ weight loss was measured, and the resulting microstructure was still quite dense. The postquench microstructure in this case consisted of MoAlB phase surrounding $\mathrm{MoB}$ grains with $\mathrm{Al}_{8} \mathrm{Mo}_{3}, \mathrm{Al}_{2} \mathrm{O}_{3}$, and $\mathrm{Al}$ dispersed uniformly as shown in Fig. 1(e).

The notable peaks in DTA with onsets at $1708 \mathrm{~K}$ (exothermic) and $1710 \mathrm{~K}$ (endothermic) are similar in area and have a small separation [Fig. 1(c)], and considering the similarity in XRD patterns before and after DTA, the peaks are most likely due to a reversible process. Based on the AlMo phase equilibria reported by Eumann et al. [31], neither Al-rich intermetallic impurity phases $\mathrm{Al}_{8} \mathrm{Mo}_{3}$ nor $\mathrm{Al}_{3+x} \mathrm{Mo}_{1-x}$ undergo any reactions in or near the 17031743-K temperature range. It follows that these peaks are most likely related to a reversible reaction involving MoAlB. The most likely explanation is that MoAlB undergoes a decomposition into $\mathrm{MoB}$ and liquid $\mathrm{Al}$ during heating and forms again into MoAlB during cooling. The presence of both MoAlB around MoB grains and $\mathrm{Al}$ after annealing and quenching under $\operatorname{Ar}$ [Fig. 1(e)] also supports the reversibility of the reaction.

Taking into consideration the high wetting angles of liquid Al with most transition-metal borides [32,33], it is likely that the liquid $\mathrm{Al}$ formed during decomposition did not wet the MoB surface, causing the observed relatively large expansion of the sample's cross-sectional area. The absence of any major new phases found in the sample bulk after DTA/TGA also supports the proposed decomposition reaction. Interestingly, the postquench microstructure indicates that the cooling rate during quenching was not sufficiently fast to prevent the reformation of MoAlB, giving rise to the core-shell microstructure shown in Fig. 1(e). At this time, the reasons for the differences in microstructures after DTA and after quenching under Ar are unknown and are beyond the scope of this paper.
As a final check of the decomposition reaction, a MoAlB sample was heated to $1773 \mathrm{~K}$ and held at that temperature for $1 \mathrm{~h}$ under vacuum and then quenched directly into cold vacuum oil. After the experiment, the sample had lost $16 \%$ of its initial mass, which accounts for nearly all the initial Al content in MoAlB. Surprisingly, the sample did not crack despite the severity of the thermal shock $(\Delta T=$ $1500 \mathrm{~K}$ ). A representative SEM micrograph of the quenched sample's surface [see Fig. 2(a)] shows a porous microstructure composed of platelike crystals and suggests that large volume changes occurred during this process, in agreement with the DTA experiment. XRD of the quenched sample in Fig. 2(b) shows that almost all the MoAlB had transformed to tetragonal MoB (space-group I4 1 /amd, ICSD No. 24280). However, no Al-rich phase is detected in this sample, presumably due to its evaporation/sublimation in the vacuum during the dwell time.

Based on the totality of these observations, it is reasonable to conclude that the following incongruent simplified reaction is occurring in this system:

$$
\mathrm{MoAlB} \leftrightarrow \mathrm{Al} \text { (liquid) }+\operatorname{MoB}(T=1708 \mathrm{~K}) .
$$

The reaction is simplified in that we assume no solubility of $\mathrm{Al}$ in $\mathrm{MoB}$. This is in agreement with the binary phase diagrams that indicate liquid $\mathrm{Al}$ and solid $\mathrm{MoB}$ are the stable phases at this temperature [31,34]. Interestingly, Sinel'nikova et al. note in an early report on MoAlB single-crystal growth that it is an incongruently melting compound [16]. In this scenario, we propose that the phase equilibria relations at 1773 $\mathrm{K}$-after the ternary phase decomposes-is $\mathrm{Al}-\mathrm{MoB}-\mathrm{Mo}_{3} \mathrm{Al}_{8}$ (on the Al-rich side) and Al-MoB- $\mathrm{MoB}_{2}$ (on the B-rich side). At this time, we do not have enough evidence to rule out the direct sublimation of $\mathrm{Al}$ especially in vacuum.

\section{Heat capacity and thermodynamic properties}

Least-squares linear fitting of $c_{\mathrm{p}} / T$ vs $T^{2}$ for 72 data points in the $4-11-\mathrm{K}$ range (not shown) yields a $\gamma$ of $1.94 \pm$ 

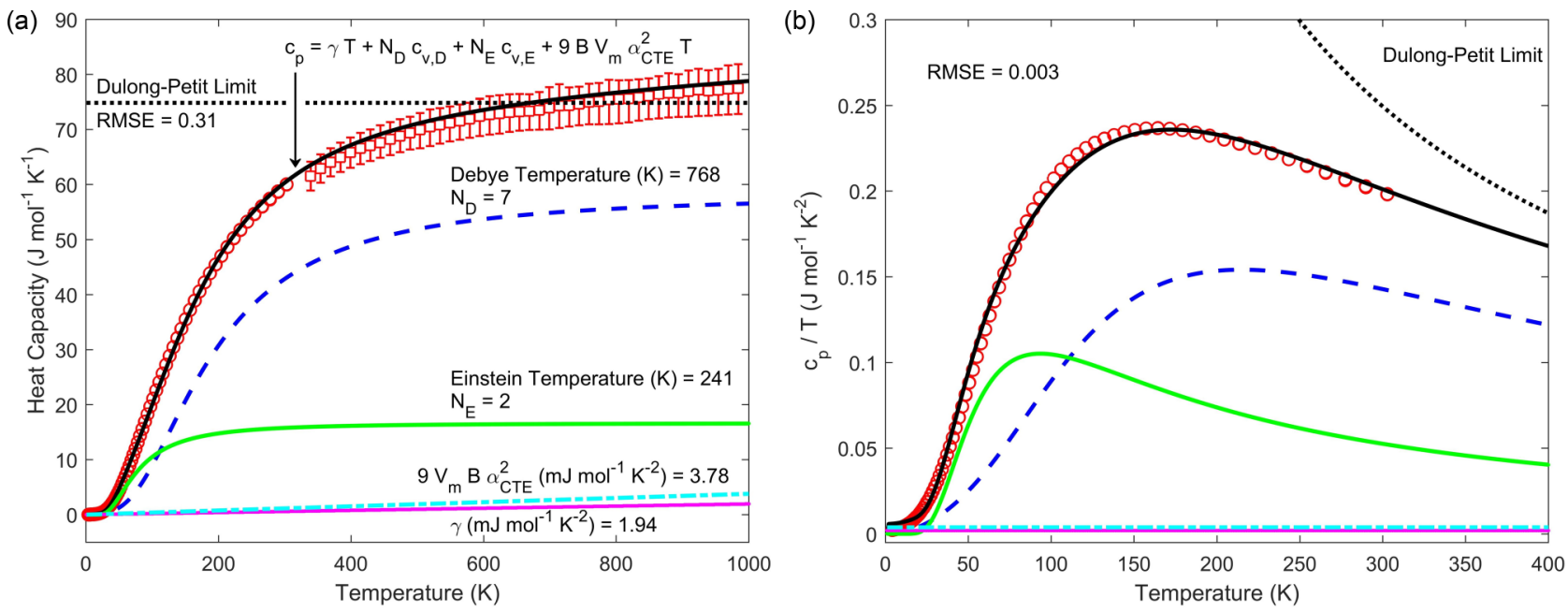

FIG. 3. (a) $c_{\mathrm{p}}$ in the 4-1000-K temperature range (red circles and squares) along with the summation (solid black line) of the constituent Debye-like $\left(c_{\mathrm{v}, \mathrm{D}}\right.$, dashed blue curve), Einstein-like $\left(c_{\mathrm{v}, \mathrm{E}}\right.$, solid green curve), electronic ( $\gamma$, purple curve), and dilation $\left(9 V_{\mathrm{m}} \beta \alpha_{\mathrm{CTE}}^{2}\right.$, light blue) contributions. The range of the three high-temperature DSC measurements are shown as error bars. (b) $c_{\mathrm{p}} / T$ vs $T$ for the lower-temperature region demonstrating the quality of the model fit. RMSE stands for root mean square error.

$0.01 \mathrm{~mJ} \mathrm{~mol}^{-1} \mathrm{~K}^{-2}$ and a $\beta$ of $18.9 \pm 0.5 \mu \mathrm{J} \mathrm{mol}^{-1} \mathrm{~K}^{-2}$ according to Eq. (1). From Eq. (2), the eDOS at the Fermi level $N\left(E_{\mathrm{f}}\right)$ was calculated to be $3.3(\mathrm{eV} \text { unit cell })^{-1}$, which is comparable to the value obtained from first principles [3.2 (eV unit cell $\left.)^{-1}\right][35,36]$ and those of some of the MAX phases [37]. Interestingly, $N\left(E_{\mathrm{f}}\right)$ for the binary MoB, which was calculated using the $\gamma$ reported by Tyan et al. [38] (i.e., $\left.2.32 \mathrm{~mJ} \mathrm{~mol}^{-1} \mathrm{~K}^{-2}\right)$, is 7.9 ( $\mathrm{eV}$ unit cell $)^{-1}$ for tetragonal MoB (space-group $I 4_{1} /$ amd). From the atomic/orbital projected eDOS calculations (not shown) $[35,36]$, both MoB and MoAlB exhibit $\mathrm{B} p$-band mixing and Mo $d$-band mixing starting at $\approx 4 \mathrm{eV}$ below $E_{\mathrm{f}}$. However, the emergence of $\mathrm{Al} p$-band mixing and Mo $d$-band mixing at $\approx 1.5 \mathrm{eV}$ below $E_{\mathrm{f}}$ in the eDOS of MoAlB is likely responsible for reducing the Mo $d$ contribution to $N\left(E_{\mathrm{f}}\right)$.

When $c_{\mathrm{p}}$ is plotted as a function of $T$, up to $1000 \mathrm{~K}$ [Fig. 3(a)], an excellent match is found between the data measured at the low- (open red circles) and the high- (open red squares with error bars) temperature ranges. The uncertainty of the low-temperature measurement is smaller than the size of the markers.

As was performed previously for the MAX phases [39], $c_{\mathrm{p}}$ was modeled as the sum of

$$
c_{\mathrm{p}}=\gamma T+N_{\mathrm{D}} c_{\mathrm{v}, \mathrm{D}}+N_{\mathrm{E}} c_{\mathrm{v}, \mathrm{E}}+9 B V_{\mathrm{m}} \alpha_{\mathrm{CTE}}^{2} T,
$$

where

$$
\begin{aligned}
c_{\mathrm{v}, \mathrm{D}}= & N_{\mathrm{D}} R\left(x_{\mathrm{D}}\right)^{-3} \int_{0}^{x_{\mathrm{D}}}\left[\left(x^{4} e^{\mathrm{x}}\right) /\left(e^{\mathrm{x}}-1\right)^{2}\right] d x \\
& \left(x_{\mathrm{D}} \equiv \theta_{\mathrm{D}} / T\right),
\end{aligned}
$$

and

$$
c_{\mathrm{v}, \mathrm{E}}=N_{\mathrm{E}} R\left(x_{\mathrm{E}}\right)^{2} e^{\mathrm{x}} /\left(e^{\mathrm{x}}-1\right)^{2} \quad\left(x_{\mathrm{E}} \equiv \theta_{\mathrm{E}} / T\right),
$$

where $N_{\mathrm{D}}$ and $N_{\mathrm{E}}$ represent the number of Debye- and Einstein-like modes such that $N_{\mathrm{D}}+N_{\mathrm{E}}=3 N$, where $N$ is the number of atoms in the formula unit ( $N=3$ for MoAlB $)$, and
$R$ is the universal gas constant. $B$ is the average bulk modulus value (220.3 GPa) over the $300-1000-\mathrm{K}$ range (Table I), and $\alpha_{\mathrm{CTE}}$ is the experimentally measured coefficient of thermal expansion $\left(9.6 \times 10^{-6} \mathrm{~K}^{-1}\right.$ [10]). A least-squares fitting of the experimental $c_{\mathrm{p}}$ data below $305 \mathrm{~K}$, shown as the solid black line in Fig. 3(a), showed that $N_{\mathrm{D}}=7$ and $N_{\mathrm{E}}=2$ produced the best fit for $c_{\mathrm{p}}$ when $\theta_{\mathrm{D}}=768 \pm 1$ and $\theta_{\mathrm{E}}=241 \pm 0.5 \mathrm{~K}$, with a root-mean-square error of $0.31 \mathrm{~J} \mathrm{~mol}^{-1} \mathrm{~K}^{-1}$ per datum. The details of the various contributions to the total also are shown in Fig. 3(a) The green line represents the Einstein model [Eq. (6)], the dashed blue line represents the Debye model [Eq. (5) and the purple and light blue, respectively, represent linear electronic and dilation terms. The quality of the low- $T$ fit is highlighted in the plot of $c_{\mathrm{p}} / T$ vs $T$ [Fig. 3(b)]. Note that, due to the uncertainty in the high- $T(T>305-\mathrm{K}) c_{\mathrm{p}}$ values, they were not included in the least-squares regression. Rather, the linear contributions to $c_{\mathrm{p}}$ were fixed by $\gamma, B$, and $\alpha_{\mathrm{CTE}}$. When the various contributions are added, they indeed

TABLE I. Temperature dependence of the shear $(G)$, Young's $(E)$, and bulk $(B)$ moduli measured by high-temperatures RUS.

\begin{tabular}{lccccccc}
\hline \hline$T(\mathrm{~K})$ & $G(\mathrm{GPa})$ & $E(\mathrm{GPa})$ & $B(\mathrm{GPa})$ & $T(\mathrm{~K})$ & $G(\mathrm{GPa})$ & $E(\mathrm{GPa})$ & $B(\mathrm{GPa})$ \\
\hline $\mathbf{3 0 0}$ & 151.2 & 372.9 & 232.9 & $\mathbf{9 2 3}$ & 141.6 & 348.2 & 214.7 \\
$\mathbf{3 2 3}$ & 151.6 & 372.4 & 228.3 & $\mathbf{9 7 3}$ & 140.6 & 345.8 & 213.2 \\
$\mathbf{3 7 3}$ & 152.4 & 372.0 & 221.9 & $\mathbf{1 0 2 3}$ & 139.5 & 343.9 & 214.2 \\
$\mathbf{4 2 3}$ & 151.7 & 371.1 & 223.2 & $\mathbf{1 0 7 3}$ & 138.7 & 342.2 & 214.1 \\
$\mathbf{4 7 3}$ & 150.9 & 368.7 & 220.6 & $\mathbf{1 1 2 3}$ & 137.9 & 339.6 & 210.8 \\
$\mathbf{5 2 3}$ & 150.1 & 367.5 & 221.8 & $\mathbf{1 1 7 3}$ & 137.1 & 340.3 & 219.3 \\
$\mathbf{5 7 3}$ & 148.9 & 364.6 & 220.3 & $\mathbf{1 2 2 3}$ & 136.3 & 338.9 & 220.1 \\
$\mathbf{6 2 3}$ & 147.8 & 362.5 & 221.0 & $\mathbf{1 2 7 3}$ & 133.8 & 330.5 & 207.5 \\
$\mathbf{6 7 3}$ & 146.5 & 360.0 & 221.2 & $\mathbf{1 3 2 3}$ & 133.8 & 329.7 & 205.0 \\
$\mathbf{7 2 3}$ & 145.5 & 357.7 & 220.0 & $\mathbf{1 3 7 3}$ & 133.1 & 327.7 & 203.1 \\
$\mathbf{7 7 3}$ & 144.5 & 355.4 & 218.9 & $\mathbf{1 4 2 3}$ & 131.7 & 323.3 & 197.5 \\
$\mathbf{8 2 3}$ & 143.7 & 353.1 & 216.6 & $\mathbf{1 4 7 3}$ & 129.8 & 319.9 & 198.9 \\
$\mathbf{8 7 3}$ & 142.5 & 350.6 & 216.5 & & & & \\
\hline \hline
\end{tabular}




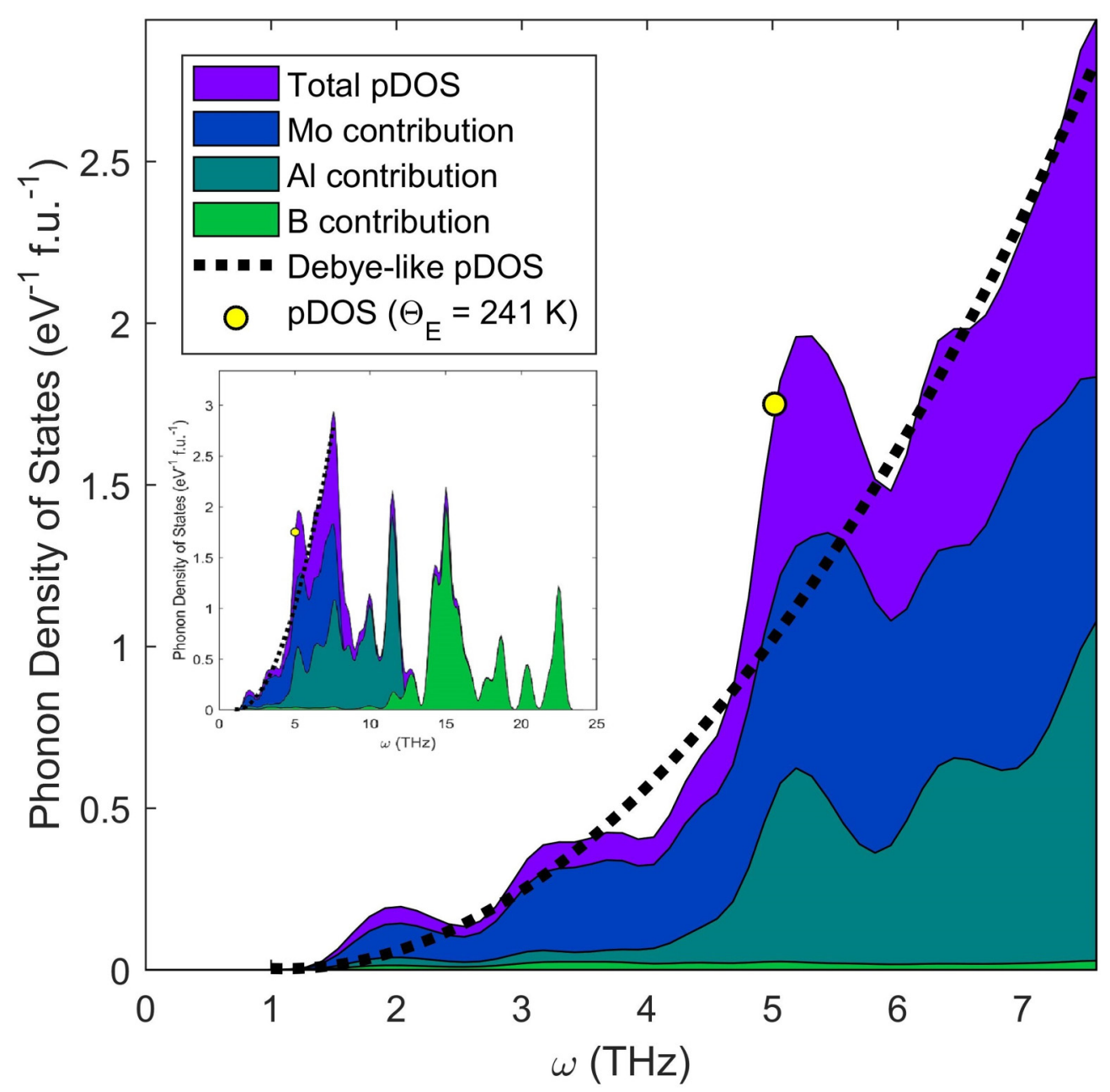

FIG. 4. Total phonon density of states (purple) and the constituent contributions from Mo (blue), Al (teal), and B (green), reported by Chaix-Pluchery et al. [14], of the acoustic region as compared to the Debye form of the pDOS (dashed black line). The value of the pDOS evaluated at $\theta_{\mathrm{E}}=241 \mathrm{~K}(5.02 \mathrm{THz})$ is shown as a yellow circle, which is near the local maximum. Inset shows the phonon density of states over the entire range of frequencies $(0-25 \mathrm{THz})$.

reproduce the experimental data nicely with $c_{\mathrm{p}}$ values quite near the mean of the three DSC measurements, the range of which are shown as error bars in Fig. 3(a).

Note that the necessity to include Einstein-like modes was determined by plotting $c_{\mathrm{p}} / T^{3}$ vs $T$, which was found to have a peak around $48 \mathrm{~K}$ (not shown). For a purely Debye-like crystal, $c_{\mathrm{v}, \mathrm{D}} / T^{3}$ cannot have a low-temperature peak. $c_{\mathrm{v}, \mathrm{E}} / T^{3}$, however, does have a maximum when $\frac{\partial}{\partial T}\left(\frac{c_{\mathrm{V}, \mathrm{E}}}{T^{3}}\right)=0$. This can be shown to occur at $T \approx \theta_{\mathrm{E}} / 5$, assuming $e^{\mathrm{x}} \gg 1$ in the denominator of Eq. (6). This is precisely the $\theta_{\mathrm{E}}$ we find from the least-squares fitting procedure. The number of Einstein-like modes $\left(N_{\mathrm{E}}=2\right)$ also was determined by least-squares fitting of Eq. (4) as $N_{\mathrm{E}}$ was increased in integer amounts from 0 to 5. It is important at this juncture to make the distinction that $N_{\mathrm{D}}$ and $N_{\mathrm{E}}$ do not represent the actual number of acoustic or optical modes in the phonon dispersion. As there can only be three acoustic modes, $N_{\mathrm{D}}=7$ does not make physical sense. Furthermore, the 18 phonon modes of MoAlB have recently been characterized by Raman spectroscopy and DFT [14]. Herein, the number of each mode can be thought of as the fractional contribution of that mode type to $c_{\mathrm{v}}$. That is $7 / 9$ of $c_{\mathrm{V}}$ is contributed by the acoustic branch and $2 / 9$ of $c_{\mathrm{V}}$ is contributed from low-energy optical modes. Lastly, as $\theta_{\mathrm{E}}=241 \mathrm{~K}$ translates to a frequency of $\omega_{\mathrm{E}}=5.02 \mathrm{THz}$ $\left(167.4 \mathrm{~cm}^{-1}\right)$, it compares well with the two lowest zone-center phonon frequencies $\left(170-210 \mathrm{~cm}^{-1}\right)$ found in the Raman spectra and the low-frequency peak in the pDOS calculated from DFT (Fig. 4) [14]. As this peak is found to break the parabolic dispersion (dashed black curve in Fig. 4) that is expected if only acoustic (Debye-like) modes are present, it corroborates our finding that optical (Einstein-like) modes must be included to accurately model the low- $T c_{\mathrm{p}}$ results.

The low- $T$ Debye temperature was calculated from

$$
\theta_{\mathrm{D}, 0}=\left(\frac{12 \pi^{4} R N_{\mathrm{D}}}{15 \beta}\right)^{1 / 3}
$$

If $N_{\mathrm{D}}$ is assumed to be $7, \theta_{\mathrm{D}, 0}=621.4 \mathrm{~K}$; if $N_{\mathrm{D}}$ is assumed to be 9 , then $\theta_{\mathrm{D}, 0}=675.7 \mathrm{~K}$. This calculation has the distinct advantage of directly probing the long-wavelength limit of the acoustical phonon dispersion as $T$ approaches $0 \mathrm{~K}$. This has some ramifications for determining the speed of sound in MoAlB as discussed below. 

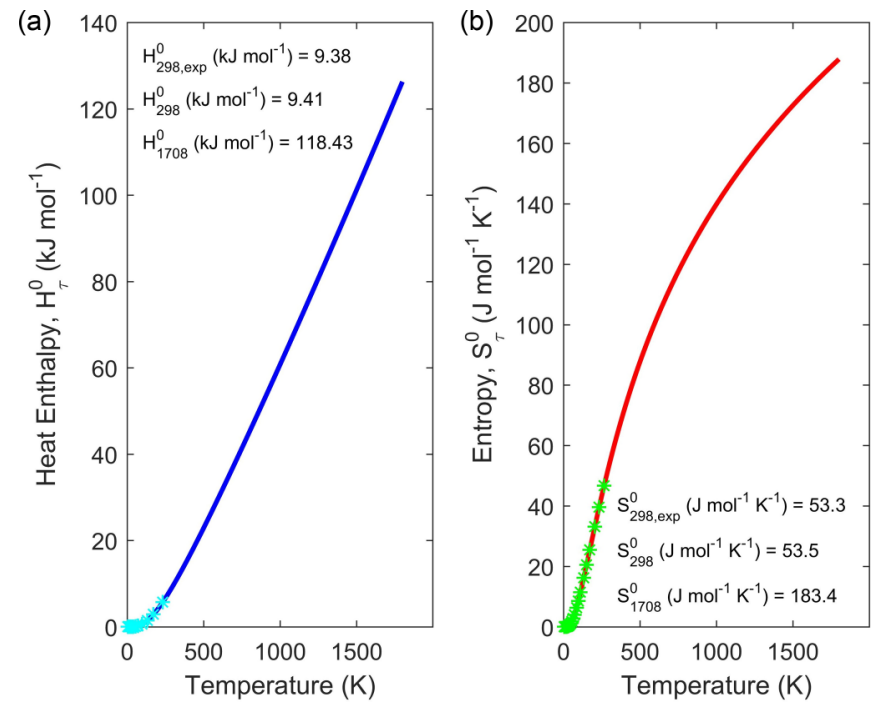

FIG. 5. (a) $H_{298}^{0}$ calculated from Eq. (8) using experimental low- $T$ $c_{\mathrm{p}}$ data (pale blue markers) and the full-range $c_{\mathrm{p}}$ model (solid blue line) and (b) $S_{298}^{0}$ calculated according to Eq. (9) using experimental low- $T c_{\mathrm{p}}$ data (green markers) and full-range $c_{\mathrm{p}}$ model (solid red line).

From $c_{\mathrm{p}}$, the heat enthalpy $H_{\tau}^{0}$ and entropy $S_{\tau}^{0}$ can be calculated according to the standard thermodynamics integrations,

$$
\begin{aligned}
& H_{\tau}^{0}=\int_{0}^{\tau} c_{\mathrm{p}}(T) d T, \\
& S_{\tau}^{0}=\int_{0}^{\tau} \frac{c_{\mathrm{p}}(T)}{T} d T .
\end{aligned}
$$

The standard enthalpy at $298 \mathrm{~K}_{298}^{0}$ was determined to be 9.38 and $9.41 \mathrm{~kJ} \mathrm{~mol}^{-1}$ from the integration of the experimental $c_{\mathrm{p}}$ and model $c_{\mathrm{p}}$ values, respectively [Fig. 5(a)]. The standard entropy at $298 \mathrm{~K} S_{298}^{0}$ was determined to be 53.3 and $53.5 \mathrm{~J} \mathrm{~mol}^{-1} \mathrm{~K}^{-1}$ from the integration of the experimental $c_{\mathrm{p}}$ and model $c_{\mathrm{p}}$ values, respectively [Fig. 5(b)]. As the percent difference in both integration results at $298 \mathrm{~K}$ was $\approx 0.3 \%$ and there was a large measurement uncertainty in the high-temperature $c_{\mathrm{p}}$ data, the model $c_{\mathrm{p}}$ [solid black line in Fig. 3(a)] was used for all further calculations over the entire temperature range.

Combining the results of the DTA, high-temperature quenching experiments, and the model $c_{\mathrm{p}}$ results, the standard enthalpy of formation of MoAlB $\Delta H_{\mathrm{f}, 298}^{0}$ was estimated using $1708 \mathrm{~K}$ as the reaction temperature for Eq. (3). In an analogous fashion to our previous work on the MAX phase $\mathrm{V}_{2} \mathrm{AlC}$ [40], $\Delta H_{\mathrm{f}, 298}^{0}$ was calculated to be $-132.0 \pm 3.2 \mathrm{~kJ} \mathrm{~mol}^{-1}$ assuming

$$
\begin{aligned}
\Delta H_{\mathrm{f}, 298, \mathrm{MoAlB}}^{0}= & \Delta G_{1708, \mathrm{Al}}^{0}+\Delta G_{1708, \mathrm{MoB}}^{0}-\left(H_{1708, \mathrm{MoAlB}}^{0}\right. \\
& \left.-H_{298, \mathrm{MoAlB}}^{0}\right)+1708 S_{1708, \mathrm{MoAlB}}^{0},
\end{aligned}
$$

where the standard Gibbs free-energy function for phase $n$ at temperature $\tau$ has the typical form

$$
\begin{aligned}
\Delta G_{\tau, \mathrm{n}}^{0} & =\Delta H_{\tau, \mathrm{n}}^{0}-T \Delta S_{\tau, \mathrm{n}}^{0} \\
& =\Delta H_{\mathrm{f}, 298, \mathrm{n}}^{0}+\left(H_{\tau, \mathrm{n}}^{0}-H_{298, \mathrm{n}}^{0}\right)-\tau S_{\tau, \mathrm{n}}^{0} .
\end{aligned}
$$

The heat enthalpy $\left(H_{\tau}^{0}-H_{298}^{0}\right)$ and entropy values for MoB were taken from the continuous functions provided by Bolgar et al. [41], and $\Delta H_{\mathrm{f}, 298, \mathrm{MoB}}^{0}=-103.9 \mathrm{~kJ} \mathrm{~mol}^{-1}$ is the value reported by Lavut et al. [42]. The thermodynamic values for Al were interpolated from the Joint-Army-Navy-Air Force (JANAF) tables [43]. The uncertainty associated with Eq. (10) $\left( \pm 3.2 \mathrm{~kJ} \mathrm{~mol}^{-1}\right)$ was estimated by adding the normalized components of the following considerations:

(i) The uncertainty reported in Ref. [42] for $\Delta H_{\mathrm{f}, 298, \mathrm{MoB}}^{0}$ is $\pm 1.2 \mathrm{~kJ} \mathrm{~mol}^{-1}$.

(ii) The error in the $c_{\mathrm{p}}$ model due to the uncertainty in $\gamma$ and the choice of $B$, resulting in an uncertainty in $\theta_{\mathrm{D}}$ and $\theta_{\mathrm{E}}$. The maximum difference in $\Delta H_{\mathrm{f}, 298, \mathrm{MoB}}^{0}$, resulting from the linear terms in Eq. (4), was $0.3 \mathrm{~kJ} \mathrm{~mol}^{-1}$.

(iii) The variance in the $c_{\mathrm{p}}$ model due to the leastsquares fitting of the low- $T$ experimental data, resulting in an uncertainty in Eqs. (8) and (9) of $\approx 0.5 \%$.

(iv) A nominal uncertainty of $1.0 \%$ was assumed for the values taken from Bolgar et al. [41] and the JANAF tables [43].

(v) Assuming the reaction temperature is accurate within $\pm 5 \mathrm{~K}$, its contribution to the uncertainty in Eq. (10) is $<0.2 \%$.

From DFT calculations on the Materials Project, the energy of formation at $0 \mathrm{~K}$ is $-128.8 \mathrm{~kJ} \mathrm{~mol}^{-1}$ [35]. This agrees quite well with the value of $-132.0 \pm 3.2 \mathrm{~kJ} \mathrm{~mol}^{-1}$ reported herein.

The thermodynamic properties of the MAX phases have been shown to be reasonably approximated from their corresponding $M X$ binary compounds [11]. This follows from the assumption that the $M-A$ bonds are as strong as the $M-X$ bonds. Applying this same approximation to MoAlB,

$$
\Delta H_{\mathrm{f}, 298, \mathrm{MoAlB}}^{0} \approx \frac{3}{2} \Delta H_{\mathrm{f}, 298, \mathrm{MoB}}^{0},
$$

we find $\Delta H_{\mathrm{f}, 298, \mathrm{MoAlB}}^{0} \approx-155.9 \mathrm{~kJ} / \mathrm{mol}$ using the $\Delta H_{\mathrm{f}, 298, \mathrm{MoB}}^{0}$ value reported by Lavut et al. [42] This estimation suggests that MoAlB is a more stable compound than what our calculation or the DFT values would suggest. This may easily be disproven by relaxing the assumption that the Mo-B bonds are as strong as the Mo-Al ones. Indeed, if we extend our approximation in Eq. (12) to be averaged with the enthalpy of the formation of a MoAl binary,

$\Delta H_{\mathrm{f}, 298, \text { MoAlB }}^{0} \approx \frac{1}{2}\left(\frac{3}{2} \Delta H_{\mathrm{f}, 298, \mathrm{MoB}}^{0}+\frac{3}{a+b} \Delta H_{\mathrm{f}, 298, \mathrm{Mo}_{a} \mathrm{Al}_{b}}^{0}\right)$,

then $\Delta H_{\mathrm{f}, 298, \text { MoAlB }}^{0} \approx-124.9 \mathrm{~kJ} / \mathrm{mol}$ using the binary MoAl $\left(\Delta H_{\mathrm{f}, 298, \mathrm{MoAl}}^{0}=-62.6 \mathrm{~kJ} / \mathrm{mol}\right) \quad[44]$ or $\Delta H_{\mathrm{f}, 298, \mathrm{MoAlB}}^{0} \approx$ $-136.9 \mathrm{~kJ} / \mathrm{mol}$ using the binary $\mathrm{Mo}_{3} \mathrm{Al}_{8}\left(\Delta H_{\mathrm{f}, 298, \mathrm{Mo}_{3} \mathrm{Al}_{8}}^{0}=\right.$ $-432.2 \mathrm{~kJ} / \mathrm{mol}$ ) [44]. Both values are again in excellent agreement with our calculation. This simple analysis provides further support that the $\mathrm{Al}$ atoms are weakly bonded. It is the "rattling" of these atoms that is primarily responsible for the low-energy optical modes that contribute to $c_{\mathrm{p}}$ (Fig. 3).

Having obtained a reliable value for $\Delta H_{\mathrm{f}, 298}^{0}$ allows for the calculation of the standard Gibbs free-energy function $\Delta G_{\mathrm{MoAlB}}^{0}$ [Eq. (11)] and the free energy of the formation of $\Delta G_{\mathrm{f}, \mathrm{MoAlB}}^{0}$, from its elements defined as

$$
\Delta G_{\mathrm{f}, \mathrm{MoAlB}}^{0}=\Delta G_{\mathrm{MoAlB}}^{0}-\Delta G_{\mathrm{Mo}}^{0}-\Delta G_{\mathrm{Al}}^{0}-\Delta G_{\mathrm{B}}^{0},
$$




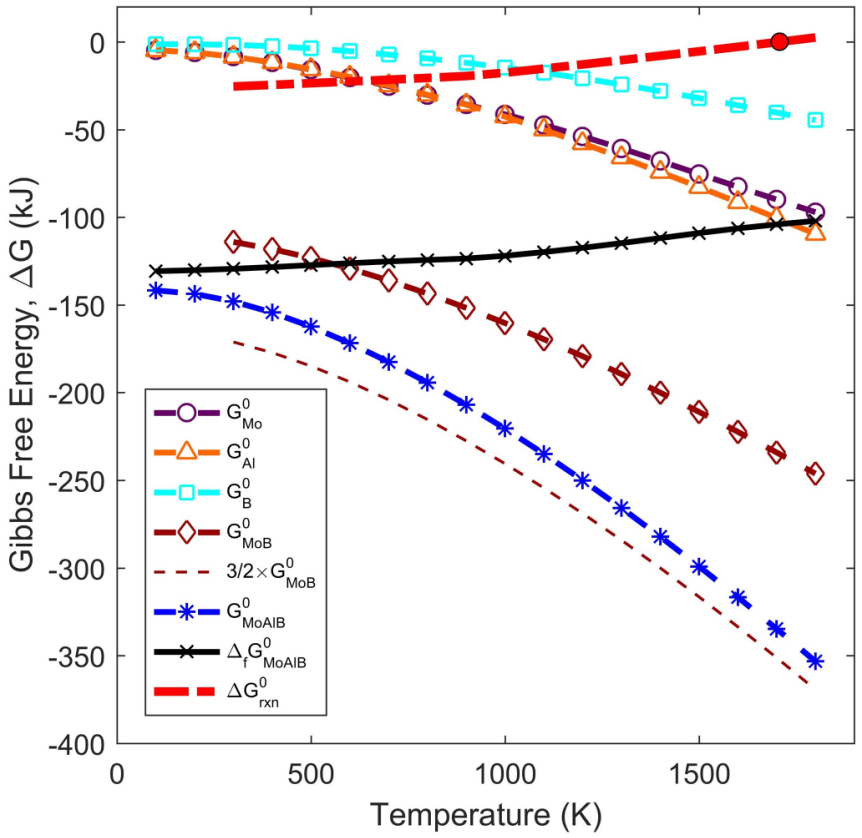

FIG. 6. Standard free-energy function of MoAlB [Eq. (11)], its free energy of formation [Eq. (14)], the free energy of the reaction for Eq. (3), and the constituent standard free energies used in the aforementioned calculations. Also shown is the (3/2) $\Delta G_{\mathrm{MoB}}$ approximation (dashed lowest line) resulting in slightly overestimated values as described in the text.

where the free energies of the elements were calculated from the JANAF tables [43]. The results of Eqs. (11) and (14) are plotted for MoAlB in Fig. 6 as dashed dark blue and solid black lines, respectively. For comparison, the same approximation made in Eq. (12) was applied to $\Delta G_{\mathrm{MoB}}^{0}$ in Fig. 6. Not surprisingly, this approximation overestimates the stability of MoAlB.

As a final check on our values, we note that the free energy of the reaction for Eq. (3) $\Delta G_{\mathrm{rxn}}^{0}$, which is just a restatement of Eq. (10), explicitly is as follows:

$$
\begin{aligned}
\Delta G_{\mathrm{rxn}}^{0} & =\sum_{\text {products }} \Delta G_{\mathrm{f}}^{0}-\sum_{\text {reactants }} \Delta G_{\mathrm{f}}^{0} \\
& =\Delta G_{\mathrm{MoAlB}}^{0}-\Delta G_{\mathrm{MoB}}^{0}-\Delta G_{\mathrm{Al}}^{0}
\end{aligned}
$$

should be equal to zero at $1708 \mathrm{~K}$. Equation (15) is plotted vs temperature in Fig. 5 (dashed red line) and does indeed cross zero at $1708 \mathrm{~K}$ (red point in Fig. 5) when MoAlB is no longer the stable phase.

Lastly, to apply these thermodynamic functions to assess the excellent oxidation properties of MoAlB, the free energies of various oxidation reactions were calculated in a manner analogous to Eq. (15) (Fig. 7). Although the pitfall of $\mathrm{ZrB}_{2}$, a promising structural ultra-high-temperature material [8], is the undesirable formation of $\mathrm{B}_{2} \mathrm{O}_{3}$ (dashed green line in Fig. 7), which becomes volatile above $\approx 700 \mathrm{~K}$ when it melts (green circle in Fig. 7), herein we find that the oxidation reaction for MoAlB proposed by Kota et al. [10] (4/3 MoAlB + $\left.\mathrm{O}_{2}=4 / 3 \mathrm{MoB}+2 / 3 \mathrm{Al}_{2} \mathrm{O}_{3}\right)$ is the most thermodynamically stable (circle markers in Fig. 7) and that the formation of other/multiple oxides is unlikely (diamond markers in Fig. 7).

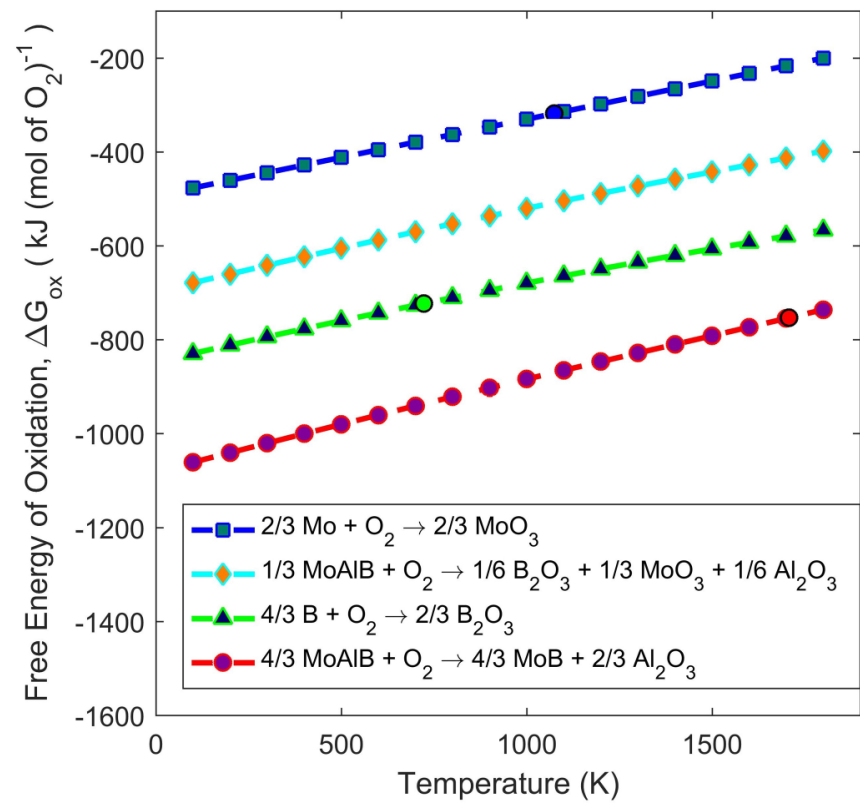

FIG. 7. Free energies of various oxidation reactions listed demonstrating the high stability of the alumina-forming MoAlB compared to the formation of other oxides.

Kinetically, the formation of the $\mathrm{Al}_{2} \mathrm{O}_{3}$ layer is proposed to be highly favorable given the weaker $\mathrm{Al}$ bonding [implied by Eq. (13)] and the low-frequency vibrations (deduced from $\theta_{\mathrm{E}}$ ) needed for diffusion. These combined attributes render MoAlB oxidation resistant and hence potentially useful for some high-temperature applications.

\section{Thermal transport}

In our previous work, we reported the thermal conductivity $\kappa_{\text {tot }}$ as a function of temperature, assuming a $c_{\mathrm{p}}$ based on the Neumann-Kopp rule. Now, using the model $c_{\mathrm{p}}$ values over the full temperature range, we recalculate and replot $\kappa_{\text {tot }}$ (Fig. 8), assuming

$$
\kappa_{\mathrm{tot}}=D \rho c_{\mathrm{p}}(T),
$$

where $D$ is the experimentally measured thermal diffusivity value and $\rho$ is the sample density $\left(6.45 \mathrm{~g} / \mathrm{cm}^{3}\right)$. Based on these results, $\kappa_{\mathrm{tot}}$ is $25.6 \mathrm{~W} \mathrm{~m}^{-1} \mathrm{~K}^{-1}$ at $373 \mathrm{~K}$ and decreases gradually to $22.3 \mathrm{~W} \mathrm{~m}^{-1} \mathrm{~K}^{-1}$ at $1073 \mathrm{~K}$. In other words, its temperature dependence is relatively weak.

To better understand $\kappa_{\mathrm{tot}}$, we first calculate the electronic $\kappa_{\mathrm{el}}$ contribution assuming — such as in the MAX phases $[45,46]$, that the Weidman-Franz law viz.,

$$
\kappa_{\mathrm{el}}=\frac{L_{\mathrm{o}} T}{r(T)}
$$

is applicable. In this relationship, $L_{\mathrm{o}}$ is the Lorenz number for a metal, $2.45 \times 10^{-8} \mathrm{~W} \Omega \mathrm{K}^{-2}$, and $r(T)$ is the temperaturedependent resistivity from Ref. [10], assumed to be linear above $300 \mathrm{~K}$. Once $\kappa_{\mathrm{el}}$ is calculated, the lattice or phonon contribution $\kappa_{\text {latt }}$ to the total is calculated assuming

$$
\kappa_{\text {latt }}=\kappa_{\mathrm{tot}}-\kappa_{\mathrm{el}} .
$$




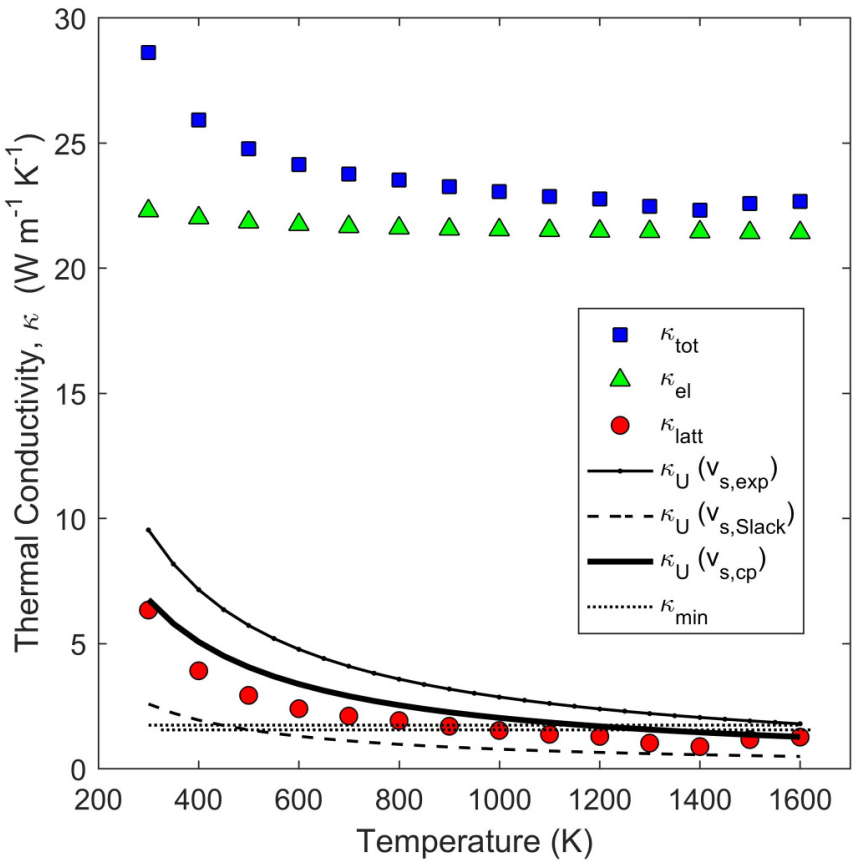

FIG. 8. Experimentally measured temperature dependence of $\kappa_{\mathrm{tot}}$ (solid blue squares), showing $\kappa_{\mathrm{el}}$ (solid green triangles) and $\kappa_{\text {latt }}$ (solid red circles). Also shown is the $\kappa_{\text {latt }}$ contribution based on the Slack [47] model for thermal conductivity using the speed of sounds $v_{\mathrm{s}}$ estimated from the speed of sound measurements $v_{\mathrm{s} \text {, exp }}$, the low-temperature Debye temperature $v_{\mathrm{s}, \mathrm{cp}}$, and from the Slack [47] method $v_{\mathrm{s} \text {, Slack. The }}$ Cahill and Pohl [51] amorphous limit $\kappa_{\min }$ (dotted black line) shows this solid approaches its fundamental limit at high temperatures.

When the various contributions are plotted (Fig. 8), one finds that, at $373 \mathrm{~K}, \kappa_{\mathrm{el}}$ accounts for $86 \%$ of $\kappa_{\mathrm{tot}}$. By $1072 \mathrm{~K}$ that fraction increases to $96 \%$. Interestingly, in the MAX phases with heavier transition-metal atoms (e.g., $\mathrm{Ta}_{2} \mathrm{AlC}$, $\mathrm{Nb}_{4} \mathrm{AlC}_{3}, \mathrm{Nb}_{2} \mathrm{AlC}$, and $\mathrm{Nb}_{2} \mathrm{SnC}$ ), the thermal conductivities from phonons are also quite low due to phonon scattering of low-lying modes or rattlers [37].

Here we model $\kappa_{\text {latt }}$ using a variation of the Slack model [47] laid out by Toberer et al. [48] for complex materials with no fitting parameters. Assuming the optical mode contributions to $\kappa_{\text {tot }}$ are negligible, the umklapp-limited lattice transport $\kappa_{\mathrm{u}}$ is given by

$$
\kappa_{\mathrm{u}}=\frac{(6 \pi)^{2 / 3}}{4 \pi^{2}} \frac{M v_{\mathrm{s}}^{3}}{T V^{2 / 3} \Gamma^{2}} \frac{1}{n_{\mathrm{D}}},
$$

where $v_{\mathrm{s}}$ is the average speed of sound in the solid, $n_{\mathrm{D}}$ is the number of atoms per unit cell that contribute to the number of Debye-like modes carrying heat $\left(N_{\mathrm{D}}=7\right), M$ is the average atomic mass per formula unit, $V$ is the volume per atom, and $\Gamma$ is the thermodynamic Grüneisen parameter. The latter was estimated assuming

$$
\Gamma=\frac{3 \alpha_{\mathrm{CTE}} B}{c_{\mathrm{v}} \rho} .
$$

Approximating $c_{\mathrm{v}}$ by the Dulong-Petit limit viz., $74.82 \mathrm{~J} \mathrm{~mol}^{-1} \mathrm{~K}^{-1}$ and using the same average bulk modulus $(220.3 \mathrm{GPa})$ in Eq. (20) yields a $\Gamma$ of 1.76 , which again is comparable to values reported for the MAX phases [37]. The estimation of $v_{\mathrm{s}}$, however, is not as straightforward. It is well known that different methods to approximate $v_{\mathrm{s}}$ can result in substantial differences $[48,49]$. Consequently, we estimate $v_{\mathrm{s}}$ in three different ways:

(i) from the temperature-averaged longitudinal $\bar{v}_{l}$ and transverse $\bar{v}_{t}$, speed of the sound measurements used to determine the elastic constants, combined in the manner summarized by Anderson [50],

$$
\bar{v}_{\mathrm{s}}=\left[1 / 3\left(2 / \bar{v}_{t}^{3}+1 / \bar{v}_{l}^{3}\right)\right]^{-1 / 3},
$$

(ii) from the low-temperature Debye temperature (621 $\mathrm{K})$ determined from $\beta$ in Eq. (1), which probes the longwavelength limit of the acoustic phonon dispersion,

(iii) from the Debye temperature as suggested by Hill [30] and Slack [47], calculated from the pDOS $g(\omega)$ shown in Fig. 3,

$$
\theta_{\infty, \text { Slack }}=\left[\frac{5 h^{2}}{3 k_{\mathrm{B}}^{2}} \frac{\int_{0}^{\omega_{a c}} \omega^{2} g(\omega) d \omega}{\int_{0}^{\omega_{a c}} g(\omega) d \omega}\right]^{1 / 2},
$$

where the latter two temperatures can be converted into $v_{\mathrm{s}}$ through the Debye relation,

$$
k_{\mathrm{B}} \theta_{\mathrm{D}}=\hbar \omega_{\mathrm{D}}=\hbar\left[6 \pi^{2} / V_{\mathrm{at}}\right]^{1 / 3} v_{\mathrm{s}},
$$

when $\omega_{\mathrm{D}}$ is found in terms of the volume per atom $V_{\text {at }}$ by integration of the Debye pDOS $\left[3 / V_{\mathrm{at}}=\int_{0}^{\omega_{\mathrm{D}}}\left(\frac{3 \omega^{2}}{2 \pi^{2} v_{\mathrm{s}}^{3}}\right) d \omega\right]$. Carrying out methods (i)-(iii) (above) resulted in $v_{\mathrm{s}}$ values of 5280,4710 , and $2820 \mathrm{~m} / \mathrm{s}$, respectively.

Additionally, the minimum lattice thermal conductivity $\kappa_{\min }$ can be estimated according to the Cahill and Pohl approximation for amorphous materials,

$$
\kappa_{\min }=\left(\frac{3}{2}\right)\left(\frac{\pi}{6 V^{2}}\right)^{1 / 3} k_{\mathrm{B}} v_{\mathrm{s}},
$$

which is $T$ independent and only depends on the atomic volume and $v_{\mathrm{s}}$ in the solid [51].

When $\kappa_{\mathrm{u}}$ and $\kappa_{\min }$ are compared to $\kappa_{\text {latt }}$ (bottom of Fig. 8), the overall agreement is surprisingly good given the simplicity of the model and the approximations that were made. It should be noted that it is generally difficult to extract $\kappa_{\text {latt }}$ for metalliclike materials and that the Slack model [47] was developed for nonmetallic solids. Nevertheless, the $1 / T$ dependence of $\kappa_{\text {latt }}$ is a signature of umklapp-dominated processes, the slope of which is matched well between the model and the experiment. Of the three estimations of $v_{\mathrm{s}}$, we find that the low-temperature Debye temperature [method (ii) above] fits the data the best $\left(v_{\mathrm{s}}=4710 \mathrm{~m} / \mathrm{s}\right)$. The Slack [47] estimation of $v_{s}$ is found to be substantially lower than the other two values, and the resulting $\kappa_{\mathrm{u}}$ does not share the same slope as our data. As the estimation of $\Gamma$ is also a likely source of error, further investigations are needed to confirm these results.

A small corroboration of our calculations, however, comes from the Cahill and Pohl [51] amorphous limit for this solid. As it is temperature independent and largely unaffected if $v_{\mathrm{s}}=4710$ or $5280 \mathrm{~m} / \mathrm{s}$, we may deduce that $\kappa_{\text {latt }}$ of MoAlB approaches its fundamental limit at high temperatures. The average $v_{\mathrm{s}}$ should therefore be within $10 \%-15 \%$ of $4700 \mathrm{~m} / \mathrm{s}$. Lastly, the calculation and analysis of $\kappa_{\text {latt }}$ suggest a large degree of anharmonicity in the lattice, which coincides with 
TABLE II. Summary of physical and thermodynamic property values for MoAlB.

\begin{tabular}{|c|c|}
\hline Property (units) & Value \\
\hline$\gamma\left(\mathrm{mJ} \mathrm{mol}^{-1} \mathrm{~K}^{-2}\right)$ & $1.94 \pm 0.01$ \\
\hline$\beta\left(\mu \mathrm{J} \mathrm{mol}^{-1} \mathrm{~K}^{-2}\right)$ & $18.9 \pm 0.5$ \\
\hline$N\left(E_{\mathrm{f}}\right)(\mathrm{eV} \text { unit cell })^{-1}$ & 3.3 \\
\hline$B_{\mathrm{HT}, \text { avg }}(\mathrm{GPa})$ & $220.3 \pm 5.1$ \\
\hline$\theta_{\mathrm{D}}(\mathrm{K}) N_{\mathrm{D}}=7$ & $768 \pm 1$ \\
\hline$\theta_{\mathrm{E}}(\mathrm{K}) N_{\mathrm{E}}=2$ & $241 \pm 0.5$ \\
\hline$\theta_{\mathrm{D}, 0}(\mathrm{~K})$ when $N_{\mathrm{D}}=7,9$ & 621,676 \\
\hline$\Delta H_{\mathrm{f}, 298, \mathrm{MoAlB}}^{0}(\mathrm{~kJ} / \mathrm{mol})$ & $-132.0 \pm 3.2$ \\
\hline$H_{298, \mathrm{MoAlB}}^{0}(\mathrm{~kJ} / \mathrm{mol})$ & 9.41 \\
\hline$S_{298, \mathrm{MoAlB}}^{0}(\mathrm{~J} / \mathrm{mol})$ & 53.5 \\
\hline$c_{\mathrm{p}, 298<T<1800, \text { MoAlB }}^{0}\left(\mathrm{~J} \mathrm{~mol}^{-1} \mathrm{~K}^{-1}\right)^{\mathrm{a}}$ & $72.363+8.73 \times 10^{-3} \mathrm{~T}-1.345 \times 10^{6} \mathrm{~T}^{-2}-9.8 \times 10^{-7} \mathrm{~T}^{2}$ \\
\hline$\Delta G_{\mathrm{f}, 100<T<1800, \operatorname{MoAlB}}^{0}(\mathrm{~kJ} / \mathrm{mol})^{\mathrm{a}}$ & $130.5+9.714 \times 10^{-4} \mathrm{~T}+8.526 \times 10^{-6} \mathrm{~T}^{2}$ \\
\hline$\Gamma$ (unitless Grüneisen parameter) & 1.76 \\
\hline$v_{\mathrm{s}, 300 \mathrm{~K}}(\mathrm{~m} / \mathrm{s})^{\mathrm{b}}$ & 5364 \\
\hline$v_{\mathrm{s}, \mathrm{cp}}(\mathrm{m} / \mathrm{s})^{\mathrm{c}}$ & 4710 \\
\hline
\end{tabular}

${ }^{a}$ Empirical fit $\left(R^{2}=0.99\right)$ of the results obtained from the explicit calculation mentioned in the text.

${ }^{\mathrm{b}}$ Average speed of sound from RUS at $300 \mathrm{~K}$ calculated from Eq. (21).

${ }^{\mathrm{c}}$ Value that best reproduces experimental $\kappa_{\text {latt }}$ data, see text.

the presence of low-energy optical phonon modes known to be effective for scattering phonons [14].

\section{CONCLUSIONS}

In conclusion, differential thermal analysis, $x$-ray diffraction, and quenching experiments were used to ascertain the thermal melting/decomposition point of MoAlB. Based on these results, we conclude that MoAlB decomposes above $\sim 1708 \mathrm{~K}$ in inert and vacuum atmospheres via incongruent melting into MoB (solid) and Al (liquid). The experimental heat capacity of MoAlB was measured up to $1000 \mathrm{~K}$ and successfully modeled as the sum of lattice, electronic, and dilation contributions. Moreover, the standard enthalpy of formation at $298 \mathrm{~K}$ was determined to be $-132.0 \pm 3.2 \mathrm{~kJ} \mathrm{~mol}^{-1}$, and the free energy of formation was calculated over the full temperature range. Additionally, the temperature dependence of thermal conductivity, recalculated using temperaturedependent $c_{\mathrm{p}}$ values, is weak and could be modeled using a variation of the Slack [47] model. The analysis contained herein gives a consistent story of the presence and implications of low-lying optical phonon modes and their contribution to $c_{\mathrm{p}}$ and thermal conductivity. Table II summarizes the physical property values calculated from the experiments conducted herein.

\section{ACKNOWLEDGMENTS}

The authors acknowledge C. Malliakas (Department of Chemistry, Northwestern University) for carrying out the low-temperature $c_{\mathrm{p}}$ measurements as well as A. Zarshenas (Department of Electrical Engineering, Illinois Institute of Technology) for his valued contributions to the regression algorithm. The authors also acknowledge Dr. G. Ying (Department of Materials Science and Engineering, Drexel University) for assisting with materials, fabrication, and valuable discussions. This work was supported, in part, by funding from the Knut and Alice Wallenberg (KAW) Foundation, Project No. 2015.0043. E.Z.-S. acknowledges EPSRC funding (Grants No. EP/M018563/1 and No. EP/M018768/1).

S.K. and M.A. contributed equally to this work.
[1] C. Martini, G. Palombarini, G. Poli, and D. Prandstraller, Wear 256, 608 (2004).

[2] B. J. Aylett, Br. Polym. J. 18, 359 (1986).

[3] E. Sani, L. Mercatelli, M. Meucci, A. Balbo, C. Musa, R. Licheri, R. Orrù, and G. Cao, Renew. Energy 91, 340 (2016).

[4] K. H. J. Buschow, Mater. Sci. Rep. 1, 1 (1986).

[5] X. W. Yu and S. Licht, J. Power Sources 179, 407 (2008).

[6] S. Licht, X. Yu, and D. Qu, Chem. Commun. (Cambridge, UK) 2, 2753 (2007).

[7] Y. Wang, X. Y. Guang, Y. L. Cao, X. P. Ai, and H. X. Yang, J. Appl. Electrochem. 39, 1039 (2009).
[8] W. G. Fahrenholtz and G. E. Hilmas, Int. Mater. Rev. 57, 61 (2012).

[9] T. A. Parthasarathy, R. A. Rapp, M. Opeka, and R. J. Kerans, Acta Mater. 55, 5999 (2007).

[10] S. Kota, E. Zapata-Solvas, A. Ly, J. Lu, O. Elkassabany, A. Huon, W. E. Lee, L. Hultman, S. J. May, and M. W. Barsoum, Sci. Rep. 6, 26475 (2016).

[11] M. W. Barsoum, Prog. Solid State Chem. 28, 201 (2000).

[12] D. J. Tallman, B. Anasori, and M. W. Barsoum, Mater. Res. Lett. 1, 115 (2013).

[13] J. L. Smialek, Corros. Sci. 91, 281 (2015). 
[14] O. Chaix-Pluchery, A. Thore, S. Kota, J. Halim, C. Hu, J. Rosen, T. Ouisse, and M. W. Barsoum, J. Raman Spectrosc. (2017).

[15] W. Jeitschko, Monatsh. Chem. 97, 1472 (1966).

[16] V. S. Sinel'nikova, V. N. Gurin, A. N. Pilyankevich, L. V. Strashinskaya, and M. M. Korsukova, J. Less-Common Met. 47, 265 (1976).

[17] Y. Yu and T. Lundström, J. Alloys Compd. 226, 5 (1995).

[18] S. Okada, Kokushikan Daigaku Kiyo 31, 7 (1998).

[19] S. Okada, K. Iizumi, K. Kudaka, K. Kudou, M. Miyamoto, Y. Yu, and T. Lundström, J. Solid State Chem. 133, 36 (1997).

[20] M. Ade and H. Hillebrecht, Inorg. Chem. 54, 6122 (2015).

[21] J. L. Smialek and A. Garg, Surf. Interface Anal. 47, 844 (2014).

[22] W. Rieger, H. Nowotny, and F. Benesovsky, Mh. Chem. 96, 844 (1965).

[23] J. Castaing, R. Caudron, G. Toupance, and P. Costa, Solid State Commun. 7, 1453 (1969).

[24] B. D. Hanson, M. Mahnig, and L. E. Toth, Z. Naturforsch., A: Astrophys., Phys. Phys. Chem. 26, 987 (1971).

[25] M. K. Drulis, H. Drulis, A. E. Hackemer, O. Leaffer, J. Spanier, S. Amini, M. W. Barsoum, T. Guilbert, and T. El-Raghy, J. Appl. Phys. 104, 023526 (2008).

[26] M. K. Drulis, H. Drulis, S. Gupta, M. W. Barsoum, and T. El-Raghy, J. Appl. Phys. 99, 093502 (2006).

[27] M. Radovic, E. Lara-Curzio, and L. Riester, Mater. Sci. Eng., A 368, 56 (2004).

[28] P. Gao, A. Bolon, M. Taneja, Z. Xie, N. Orlovskaya, and M. Radovic, Solid State Ionics 300, 1 (2017).

[29] R. W. Hertzberg, Deformation and Fracture Mechanics of Engineering Materials, 5th ed. (Wiley, New York, 1989).

[30] R. Hill, Proc. Phys. Soc., London, Sect. A 65, 349 (1952).

[31] M. Eumann, G. Sauthoff, and M. Palm, Int. J. Mater. Res. 97, 1502 (2006).

[32] G. A. Yasinskaya, Sov. Powder Metall. Met. Ceram. 5, 557 (1966).

[33] G. V Samsonov, A. D. Panasyuk, G. K. Kozina, and L. V. D’yakonova, Sov. Powder Metall. Met. Ceram. 11, 568 (1972).
[34] H. Okamoto, J. Phase Equilibria Diffus. 31, 492 (2010).

[35] A. Jain, S. P. Ong, G. Hautier, W. Chen, W. D. Richards, S. Dacek, S. Cholia, D. Gunter, D. Skinner, G. Ceder, and K. A. Persson, APL Mater. 1, 011002 (2013).

[36] X. Li, H. Cui, and R. Zhang, Sci. Rep. 6, 39790 (2016).

[37] M. W. Barsoum, MAX Phases Prop. Mach. Ternary Carbides Nitrides, 1st ed. (Wiley-VCH, Weinheim, 2013), pp. 107-115.

[38] Y. S. Tyan, E. T. Louis, and Y. A. Chang, J. Phys. Chem. Solids 30, 785 (1969).

[39] M. K. Drulis, A. Czopnik, H. Drulis, J. E. Spanier, A. Ganguly, and M. W. Barsoum, Mater. Sci. Eng., B 119, 159 (2005).

[40] M. T. Agne and M. W. Barsoum, J. Alloys Compd. 665, 218 (2016).

[41] A. S. Bolgar, A. V. Blinder, and M. I. Serbova, Sov. Powder Metall. Met. Ceram. 29, 977 (1990).

[42] E. G. Lavut, N. V. Chelovskaya, and O. E. Kashireninov, J. Eng. Phys. Thermophys. 65, 971 (1993).

[43] M. W. Chase, JANAF Thermochemical Tables, Am. Chem. Soc. New York, Am. Inst. Phys. Natl. Bur. Stand. c1986, US Natl. Bur. Stand. (1986), p. 1, http://adsabs.harvard.edu/abs/1986jtt..book.....C.

[44] I. Shilo and H. F. Franzen, J. Electrochem. Soc. 129, 2613 (1982).

[45] M. W. Barsoum, I. Salama, T. El-Raghy, J. Golczewski, H. J. Seifert, F. Aldinger, W. D. Porter, and H. Wang, Metall and Mat Trans A 33, 2775 (2002).

[46] M. W. Barsoum, C. J. Rawn, T. El-Raghy, A. T. Procopio, W. D. Porter, H. Wang, and C. R. Hubbard, J. Appl. Phys. 87, 8407 (2000).

[47] G. A. Slack, Solid-State Physics, 1st ed. (Academic, New York, 1979), Vol. 34.

[48] E. S. Toberer, A. Zevalkink, and G. J. Snyder, J. Mater. Chem. 21, 15843 (2011).

[49] R. Bruls, H. T. Hintzen, and R. Metselaar, J. Appl. Phys. 98, 126101 (2005).

[50] O. L. Anderson, J. Phys. Chem. Solids 24, 909 (1963).

[51] D. G. Cahill and R. O. Pohl, Annu. Rev. Phys. Chem. 39, 93 (1988). 